\title{
24S-Hydroxycholesterol Is Associated with Agitation Severity in Patients with Moderate-to-Severe Alzheimer's Disease: Analyses from a Clinical Trial with Nabilone
}

\author{
Myuri Ruthirakuhan ${ }^{\mathrm{a}, \mathrm{b}}$, Nathan Herrmann ${ }^{\mathrm{b}, \mathrm{c}}$, Ana C. Andreazza ${ }^{\mathrm{b}}$, Nicolaas Paul L.G. Verhoeff ${ }^{\mathrm{d}}$, \\ Damien Gallagher ${ }^{\mathrm{a}}$, Sandra E. Black ${ }^{\mathrm{a}, \mathrm{e}}$, Alex Kiss ${ }^{\mathrm{a}, \mathrm{f}}$ and Krista L. Lanctôt ${ }^{\mathrm{a}, \mathrm{b}, \mathrm{c}, *}$ \\ ${ }^{a}$ Hurvitz Brain Sciences Program, Sunnybrook Research Institute, Toronto, ON, Canada \\ ${ }^{\mathrm{b}}$ Department of Pharmacology and Toxicology, University of Toronto, Toronto, ON, Canada \\ ${ }^{\mathrm{c}}$ Department of Psychiatry, Sunnybrook Health Sciences Centre, Toronto, ON, Canada \\ ${ }^{\mathrm{d}}$ Department of Psychiatry, Baycrest Health Sciences Centre, Toronto, ON, Canada \\ ${ }^{\mathrm{e}}$ Department of Medicine (Neurology), University of Toronto and Sunnybrook HSC, Toronto, ON, Canada \\ ${ }^{\mathrm{f}}$ Department of Research Design and Biostatistics, Sunnybrook Research Institute, Toronto, ON, Canada
}

Accepted 13 June 2019

\begin{abstract}
.
Background: Agitation is a prevalent and difficult-to-treat symptom of Alzheimer's disease (AD). The endocannabinoid system (ECS) has been a target of interest for the treatment of agitation. However, ECS signaling may interact with AD-related changes in brain cholesterol metabolism. Elevated brain cholesterol, reflected by reduced serum 24-S-hydroxycholesterol (24S-OHC), is associated with reduced membrane fluidity, preventing ligand binding to cannabinoid receptor 1.

Objective: To assess whether $24 \mathrm{~S}-\mathrm{OHC}$ was associated with agitation severity and response to nabilone.

Methods: 24S-OHC was collected from AD patients enrolled in a clinical trial on nabilone at the start and end of each phase. This allowed for the cross-sectional and longitudinal investigation between 24S-OHC and agitation (Cohen Mansfield Agitation Inventory, CMAI). Post-hoc analyses included adjustments for baseline standardized Mini-Mental Status Exam (sMMSE), and analyses with CMAI subtotals consistent with the International Psychogeriatric Association (IPA) definition for agitation (physical aggression and nonaggression, and verbal aggression).

Results: 24S-OHC was not associated with CMAI scores cross-sectionally or longitudinally, before and after adjusting for baseline sMMSE. However, 24S-OHC was associated with greater CMAI IPA scores at baseline $(\mathrm{F}(1,36)=4.95, p=0.03)$. In the placebo phase only, lower $24 \mathrm{~S}-\mathrm{OHC}$ at baseline was associated with increases in CMAI IPA scores $(\mathrm{b}=-35.2,95 \% \mathrm{CI}$ -65.6 to $-5.0, p=0.02)$, and decreases in 24S-OHC were associated with increases in CMAI IPA scores $(b=-20.94,95 \% \mathrm{CI}$ -57.9 to $-4.01, p=0.03)$.
\end{abstract}

Conclusion: 24S-OHC was associated with agitation severity cross-sectionally, and longitudinally in patients with AD. However, 24S-OHC did not predict treatment response, and does not change over time with nabilone.

Keywords: Alzheimer's disease, behavioral symptoms, biomarkers, geriatric psychiatry

\footnotetext{
*Correspondence to: Dr. Krista L Lanctôt, PhD, 2075 Bayview Avenue, Room FG-08, Toronto, Ontario, M4N 3M5, Canada. Fax: +1 416480 6022; E-mail: krista.lanctot@ sunnybrook.ca.
} 


\section{INTRODUCTION}

Agitation is one of the most prevalent and difficult-to-treat neuropsychiatric symptoms (NPS) of Alzheimer's disease (AD) and is more likely to occur in the more advanced stages of the disease [1-7]. Its presence is associated with faster progression to severe $\mathrm{AD}$, increased likelihood of death, decreases in quality of life, and increases in caregiver burden and rates of institutionalization [8-11]. Current recommendations for the management of agitation include the judicious use of atypical antipsychotics which have modest efficacy and harmful side-effects, such as increased mortality, Parkinsonism, and adverse cerebrovascular events [12-14]. As such, identifying safer and more effective pharmacotherapies for the treatment of agitation in $\mathrm{AD}$ is a priority. One major difficulty in reaching this objective is the lack of biomarkers available for agitation in $\mathrm{AD}$ patients. These biomarkers would be particularly useful if they could identify patients for a specific pharmacotherapy, or monitor treatment response. Identifying a biomarker of agitation, and finding alternative treatments which are both effective and safe for the management of agitation in $\mathrm{AD}$ are therefore an important research focus.

Abnormal brain cholesterol metabolism, which reflects pathological processes, has been investigated and implicated in AD pathophysiology [15-17]. 24S-hydroxycholesterol (24S-OHC) is enzymatically oxidized in the brain from cholesterol by cytochrome P450 46A1 (CYP46A1) [18]. As 24S$\mathrm{OHC}$ is the only cholesterol metabolite able to effectively pass the blood-brain barrier, it can be measured in the periphery and reflects $90 \%$ of cholesterol levels in the brain $[19,20]$. However, its relationship with pathological aging is complicated. In healthy aging and in the early stages of cognitive impairment, 24S-OHC levels in the periphery are proportional to cholesterol levels in the brain. During pathological aging and in the severe stages of $\mathrm{AD}$, there is a reduction in the production of $24 \mathrm{~S}-\mathrm{OHC}$ due to neuronal cell death and the inability to produce CYP46A1 [21, 22]. These pathological changes result in an inverse relationship between $24 \mathrm{~S}-\mathrm{OHC}$ levels in the periphery and cholesterol levels in the brain. High brain cholesterol levels reduce membrane fluidity [23], which may have implications for pharmacotherapy.

One example of an endogenous neurotransmitter system impacted by changes in membrane fluidity is the endocannabinoid system (ECS), which has been associated with NPS such as agitation and anxiety in animal models [24-26]. Specifically, elevated brain cholesterol levels reduce the efficacy at which cannabinoids $(\mathrm{CB})$ bind to $\mathrm{CB}$ receptor 1 [21, $27,28]$, a key component of the ECS, resulting in attenuation of ECS signaling. Elevated cholesterol levels in the brain, which can be quantified by reduced 24S-OHC levels in the periphery, might be potentially useful as a biomarker to reflect the occurrence and/or severity of agitation in patients with moderateto-severe AD by modulating the ECS.

24S-OHC may also be relevant to treatment. Targeting the ECS exogenously with $\mathrm{CBs}$ such as nabilone, a partial agonist at $\mathrm{CB} 1 / 2$, has gained interest as a method to treat agitation. In a singlecase study with nabilone, Passmore (2008) reported an improvement in agitation over 6 weeks [29]. However, that study was significantly underpowered as this was an $\mathrm{N}$ of 1 study. Our group recently completed the first placebo-controlled, double-blind randomized controlled trial with nabilone for agitation in 38 patients with moderate-to-severe AD patients. That study reported that nabilone significantly improved agitation, overall NPS, and cognition compared to placebo [30]. The reported efficacy of nabilone on agitation may be the result of its biological effects on brain cholesterol metabolism. Specifically, in vitro studies have demonstrated that activation of the $\mathrm{CB}$ receptors have anti-inflammatory and anti-oxidant effects [31, 32], which may in turn alter CYP46A1 activity. Therefore, nabilone may be able to improve agitation through a reduction of brain cholesterol levels by increasing the production of 24S-OHC due to altered CYP46A1 activity.

The goals of this study were to investigate the cross-sectional and longitudinal relationship between 24S-OHC and agitation. 24S-OHC samples were collected from a clinical trial investigating the safety and efficacy of nabilone for agitation in patients with AD. The associations between baseline 24S$\mathrm{OHC}$ and changes in agitation severity in nabilone versus placebo, and between changes in $24 \mathrm{~S}-\mathrm{OHC}$ and changes in agitation severity in nabilone versus placebo, allowed us to investigate whether $24 \mathrm{~S}-\mathrm{OHC}$ could predict response to nabilone, and whether nabilone could affect brain cholesterol metabolism.

\section{METHODS}

Samples were collected from a clinical trial investigating the safety and efficacy of nabilone in agitated patients with moderate-to-severe $\mathrm{AD}$ 
(NCT02351882). This was a 14-week randomized, double-blind, placebo-controlled cross-over trial comparing 6 weeks of nabilone $(1-2 \mathrm{mg})$ to 6 weeks of matched placebo, with a 1-week washout between treatment phases. This study was approved by the Research Ethics Board at Sunnybrook Health Sciences Centre and a No Objection Letter was issued by Health Canada. Study procedures were conducted in accordance with the Declaration of Helsinki and the International Conference on Harmonisation Consolidated Guidelines on Good Clinical Practice.

\section{Study patients}

Patients who met The Diagnostic and Statistical Manual (DSM-5) criteria for major neurocognitive disorder (NCD) due to $\mathrm{AD}$, and patients with both major NCD due to AD and major vascular NCD (e.g., mixed $\mathrm{AD}$ and cerebrovascular disease), who scored 24 or less on the standardized Mini-Mental Status Exam (sMMSE) and who had clinically significant agitation (Neuropsychiatric Inventory (NPI)agitation/aggression subscore $\geq 3$ ), were recruited from Sunnybrook's long term care veterans' center or outpatient psychiatry clinics in the Greater Toronto Area (Ontario, Canada). Eligible participants also had to be greater than 55 years of age, and if treated with a psychotropic or cognitive-enhancing medication, the dosage had to be stable for a minimum of 1 and 3 months, respectively. Patients were excluded if they had a contraindication or history of hypersensitivity to any cannabinoid, uncontrolled cardiovascular disease, or presence or history of other psychiatric or neurological conditions.

\section{Study design}

\section{Schedule}

Assessments were conducted on the following weeks: -1 (screening), 0 (baseline, start of treatment 1), 2, 4, 6 (assessment was conducted within first three days; start of placebo washout), 8 (start of treatment 2), 10, 12, 14 (final assessment), and 15 (safety follow-up).

\section{Study intervention}

Enrolled participants started with one week of placebo run-in (week -1). During week 0, $0.25 \mathrm{mg}$ doses ( 1 capsule) were given before bedtime for the first three nights, then 1 capsule $(0.25 \mathrm{mg}$ each or placebo) BID for four days. Participants were then given 1 capsule $(0.5 \mathrm{mg}$ total or placebo) daily dur- ing week 1. Study dose was increased to 1 capsule BID (1 mg total or placebo) during week 2. During weeks 3 and 4, the dose was increased to a maximum of 2 capsules BID ( $2 \mathrm{mg} / \mathrm{d}$ total or placebo) or decreased based on tolerability. This dose was maintained until down-titration in week 6 . Following the first three days of week 6 , there was a taper phase for the remaining 4 days in order to reduce the risk of potential withdrawal effects of active treatment.

\section{Assessments}

Agitation was assessed using the Cohen Mansfield Agitation Inventory (CMAI), a 29-point scale that measures agitation in two dimensions, verbal and physical, each of which have two poles, aggressive and non-aggressive [33]. Higher scores on the CMAI reflect greater severity of agitation.

\section{Analysis of $24 \mathrm{~S}-\mathrm{OHC}$}

$24 \mathrm{~S}-\mathrm{OHC}$ was collected from serum at four time points; the start and end of each treatment phase, and were frozen $\left(-80^{\circ} \mathrm{C}\right)$ immediately and batched for analysis. Serum samples were shipped to the Metabolomics Facility at Washington University School of Medicine (St. Louis, MO) for analysis. Serum 24S-OHC levels were quantified using a highly sensitive 2D-liquid chromatography and tandem mass spectrometry (LC-MS/MS) assay that was developed for the quantification of $24 \mathrm{~S}-\mathrm{OHC}$ in human plasma and cerebrospinal fluid (CSF) [34].

\section{Statistical analyses}

\section{Primary aim}

The cross-sectional relationship between BL concentrations of serum 24S-OHC and BL CMAI scores was determined using a linear regression.

\section{Secondary aim}

The relationship between BL levels of serum 24SOHC on CMAI total score over time was determined using a linear mixed model with participants as a random factor and a block size of 8 levels (weeks 0 (BL), 2, 4, 6, 8, 10, 12, and 14). Time and BL biomarker levels were included as fixed factors. The main effects of BL biomarker levels, time and the BL biomarker $\mathrm{x}$ time interaction term were computed in the linear mixed model (total: 3 covariates). As we were unable to add treatment group as a fourth covariate due an underpowered sample size, we completed separate linear mixed models in the nabilone phase, and placebo phase. 


\section{Exploratory aim}

The longitudinal relationship between 24S-OHC and CMAI total score over time was determined using a linear mixed model. Time and biomarker levels were included as fixed factors. The main effects of biomarker levels, time, and the biomarker $\mathrm{x}$ time interaction term were computed in the linear mixed model (total: 3 covariates). As previously mentioned in the secondary hypothesis, due to an underpowered sample size, we completed separate linear mixed models in the nabilone phase, and placebo phase to investigate treatment effects.

\section{Post-hoc analyses}

1) As $24 \mathrm{~S}-\mathrm{OHC}$ may be sensitive to changes in AD severity, the diagnostic, predictive, and monitoring analyses included baseline sMMSE scores as a covariate.

2) The International Psychogeriatric Association (IPA) has defined agitation in $\mathrm{AD}$ as either physical aggression, physical nonaggression, or verbal aggression symptoms that are frequent or persistent for at least two weeks [35]. To measure this, we summed the 3 relevant CMAI subscores (physical aggression + physical nonaggression + verbal aggression) and designated the sum score as CMAI IPA. Higher CMAI IPA scores reflect greater agitation severity.

\section{Power calculation}

The sample size of this project was dictated by the sample size for NCT02351882, the study from which we recruited participants. That study investigated the safety and efficacy of nabilone in the treatment of moderate-to-severe patients with $\mathrm{AD}$ and aimed to randomize 40 participants. As our primary hypothesis was that levels of $24 \mathrm{~S}-\mathrm{OHC}$ (objective 1) would be correlated with severity of agitation at BL, a mediumto-large effect size would require 29 participants in total for a power of 0.8 and an alpha of 0.05 .

\section{RESULTS}

Thirty-nine patients were enrolled between September 2015 and December 2017. One participant was discontinued during the placebo run-in (week-1) due to clinically significant delusions, resulting in a study total of 38 participants. Study demographics, medical history, and baseline assessment measures are included in Table 1.24S-OHC was collected from all 38 participants at baseline. $24 \mathrm{~S}-\mathrm{OHC}$ from follow-
Table 1

Baseline demographics, medical history, cognitive and behavioral assessments, and baseline 24S-OHC levels $(\mathrm{N}=38)$

\begin{tabular}{lc}
\hline & Mean $( \pm \mathrm{SD})$ \\
\hline Demographics & $87(10)$ \\
Age & 77 \\
Males (\%) & 72 \\
Inpatients (\%) & \\
Medical History & $6(3)$ \\
$\quad$ Number of comorbid illnesses & $12(5)$ \\
$\quad$ Number of concomitant medications & $2(1)$ \\
$\quad$ Number of psychotropic medications & \\
Cognitive and Behavioral Assessments & $7(7)$ \\
Standardized Mini-Mental Status Examination & $7(3)$ \\
Neuropsychiatric Inventory - Agitation subscale & $68(18)$ \\
Cohen Mansfield-Agitation Inventory & $22(11)$ \\
$\quad$ Physical/aggressive & $24(8)$ \\
Physical/nonaggressive & $8(4)$ \\
$\quad$ Verbal/aggressive & $14(7)$ \\
$\quad$ Verbal/nonaggressive & \\
Serum 24S-OHC levels & $14.3(5.2)$ \\
24S-OHC (ng/mL) &
\end{tabular}

24S-OHC, 24S-hydroxycholesterol.

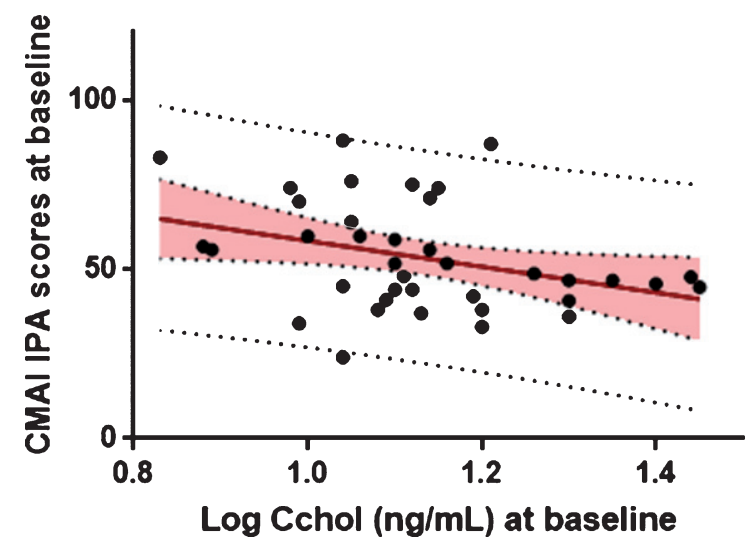

Fig. 1. Association between baseline $\log 24 \mathrm{~S}-\mathrm{OHC}$ and baseline CMAI IPA scores.

up was available in 34 participants in the nabilone phase, and 35 participants in the placebo phase. As 24S-OHC levels were not normally distributed across the patient group, $24 \mathrm{~S}-\mathrm{OHC}$ was log-transformed for all analyses.

\section{Primary aim}

BL 24S-OHC levels were not significantly associated with CMAI total scores at BL, before and after adjusting for BL sMMSE scores. However, lower levels of $24 \mathrm{~S}-\mathrm{OHC}$ at BL were significantly associated with greater CMAI IPA scores at baseline $(\mathrm{F}(1$, 36) $=4.95, p=0.03)($ Fig. 1). 


\section{Secondary aim}

\section{Nabilone phase}

BL 24S-OHC levels did not predict changes in CMAI total scores over time, before and after adjusting for BL sMMSE scores. BL 24S-OHC levels also did not predict changes in CMAI IPA scores over time.

\section{Placebo phase}

Greater 24S-OHC levels at baseline were significantly associated with decreases in CMAI total scores over time ( $\mathrm{b}=-35.2,95 \% \mathrm{CI}-65.6$ to $-5.0, p=0.02)$. After adjusting for BL MMSE scores, BL 24S-OHC levels did not predict changes in CMAI total scores. BL 24S-OHC levels predicted changes in CMAI IPA scores over time $(b=-37.4,95 \% \mathrm{CI}-65.8$ to -9.05 , $p=0.01$.

\section{Exploratory aim}

\section{Nabilone phase}

Changes in 24S-OHC levels were not associated with changes in CMAI total scores, before and after adjusting for BL MMSE scores. Changes in 24SOHC levels were also not associated with changes in CMAI IPA scores over time.

\section{Placebo phase}

Increases in 24S-OHC levels trended significance in their association with decreases in CMAI total scores $(b=-30.9,95 \% \mathrm{CI}-62.6$ to $0.90, p=0.06)$. However, after adjusting for BL MMSE scores, changes in 24S-OHC levels were not associated with CMAI total scores over time. Increases in 24S-OHC levels were significantly associated with decreases in CMAI IPA scores over time $(b=-30.94,95 \%$ CI -57.9 to $-4.01, p=0.03$ ).

\section{DISCUSSION}

The findings of this study suggest that 24S-OHC may be a marker of agitation severity, and a marker of change in agitation severity in patients with $\mathrm{AD}$. With regards to our longitudinal results, there were no significant findings in the nabilone phase, suggesting that either nabilone does not have a significant effect on brain cholesterol metabolism, or that nabilone is able to stabilize $24 \mathrm{~S}-\mathrm{OHC}$ levels through an alternative biological mechanism.

This is the first study to report on the association between $24 \mathrm{~S}-\mathrm{OHC}$ and agitation in patients with $\mathrm{AD}$, and one of few to report on the relationship between 24S-OHC and any NPS. In in vitro studies with human-derived cells, brain cholesterol levels have been linked to elevated dopaminergic $[36,37]$ and noradrenergic [38] activity, and reduced serotonergic [39] and gamma-aminobutyric acid (GABA) [40] activity. Changes in the activity of these neurotransmitter systems have been associated with increased agitation in patients with dementia in pharmacochallenge, imaging, genetic, and drug-trial studies [41-49]. Furthermore, clinical, imaging, and animal model studies have supported interactions between the ECS, a brain signaling pathway involved in the regulation of agitation, and the dopaminergic, noradrenergic, serotonergic, and GABA neurotransmitter systems [50-56]. This suggests that reduced membrane fluidity due to increased cholesterol, may be associated with increased agitation severity due to attenuation of the ECS, which in turn may alter neurotransmitter signaling which further exacerbates agitation. Two studies have investigated the association between $24 \mathrm{~S}-\mathrm{OHC}$ and depression $[18,57]$. One study compared plasma $24 \mathrm{~S}-\mathrm{OHC}$ levels between patients with $\mathrm{AD}$, vascular dementia $(\mathrm{VaD})$, depression, and healthy controls [18], while another study compared plasma $24 \mathrm{~S}-\mathrm{OHC}$ to cholesterol ratio between patients with $\mathrm{AD}, \mathrm{VaD}$, mild cognitive impairment, depression, and healthy controls [57]. Of relevance to interpretation, the MMSE scores of the mild cognitive impairment, $\mathrm{AD}$, and $\mathrm{VaD}$ groups in both studies were greater than 17 , placing patients in the mild-to-moderate stages of dementia severity, as opposed to the more advanced stages included in this study. Both studies reported significantly greater 24S-OHC [18], and 24S-OHC:cholesterol levels [57] in patients with cognitive impairment compared to patients with depression and healthy controls. Given the level of cognitive severity of these patients, this finding was expected. Both studies also reported comparable 24S-OHC [18], and 24S-OHC:cholesterol levels [57] between depressed patients and healthy controls. However, since MMSE scores were not significantly different between depressed and healthy control groups, and were significantly lower in the cognitively impaired groups, these findings suggest that brain cholesterol metabolism may be better suited as a marker of cognitive severity than NPS. In contrast, this study included patients in the more severe stages of $\mathrm{AD}$, and therefore $24 \mathrm{~S}-\mathrm{OHC}$ levels may be a marker of clinical characteristics other than cognition, such as agitation, in the more advanced stages of $\mathrm{AD}$. 
In our longitudinal analyses, findings in the placebo phase indicated that lower levels of 24S$\mathrm{OHC}$ at $\mathrm{BL}$, and decreases in $24 \mathrm{~S}-\mathrm{OHC}$ from $\mathrm{BL}$ to study endpoint were associated with increases in agitation severity. Our lack of findings in the nabilone phase may suggest the potential of nabilone to stabilize 24S-OHC levels and subsequent brain cholesterol levels. Brain cholesterol is metabolized to 24S-OHC through CYP46A1 metabolism. In vitro studies have demonstrated that the expression and activity of this enzyme is influenced by oxidative stress and neuroinflammation, two processes known to be exacerbated with AD pathology [58-61]. Preclinical and clinical studies with THC have demonstrated its potential benefits on oxidative stress $[62,63]$ and neuroinflammation $[64,65]$ through CB1/2. This suggests that nabilone may also have antioxidant and antiinflammatory effects, which in turn may stabilize the production of 24S-OHC through the modulation of CYP46A1 expression and activity. However, this cannot be confirmed due to a lack of evidence reporting on the antioxidant and anti-inflammatory properties of nabilone. In vitro and preclinical studies investigating the anti-inflammatory and anti-oxidant effects of nabilone would be of value since nabilone differs both pharmacokinetically and pharmacodynamically from THC, and may also have varying downstream effects.

Several neuroimaging studies support an association between brain cholesterol metabolism and ADrelated brain changes which may in turn exacerbate agitation severity. Increased brain hypometabolism, as measured by ${ }^{18} \mathrm{~F}$-fludeoxyglucose (FDG)-positron emission tomography (PET) has been associated with increased severity of cognitive impairment [66-68], NPS [69], and agitation [70, 71]. Interestingly, cholesterol-related genes were found to be associated with hypometabolism in AD-affected brain areas, after controlling for apolipoprotein E4 status, a gene involved in cholesterol transport [72]. This suggests that AD-related changes in brain hypometabolism, are likely associated with changes in brain cholesterol metabolism. However, no studies have investigated the relationship between ${ }^{18} \mathrm{~F}-\mathrm{FDG}$ PET uptake and peripheral 24S-OHC to confirm this relationship. Central cholesterol retention has also been linked to $\mathrm{AD}$-specific biomarker pathologies such as increased amyloid- $\beta(A \beta)$ plaques and tauinduced neurofibrillary tangles. An in vitro study reported that cholesterol retention in the AD brain was associated with increased $\beta$ - and $\gamma$-secretase, which are enzymes responsible for the breakdown of the amyloid- $\beta$ protein precursor, resulting in an accumulation in $A \beta$ plaques [73]. One study with an AD-rat model reported that cholesterol in the CSF was associated with tau hyperphosphorylation and subsequent memory deficits [74]. Therefore, altered brain cholesterol metabolism may be associated with increased AD pathology. Since evidence from postand antemortem studies support a link between $A \beta$ and tau pathology and agitation in patients with $\mathrm{AD}$ [75], it is possible that altered brain cholesterol metabolism worsens AD pathology, which may in turn be associated with increased agitation severity in patients with AD. However, future studies should investigate this relationship further to provide insight regarding the relationship between brain cholesterol metabolism and AD pathology in agitated patients with AD.

Most literature reporting on the relationship between 24S-OHC and AD report greater levels of $24 \mathrm{~S}-\mathrm{OHC}$ in the periphery of AD patients compared to healthy controls [21]. However, those studies included patients who were of milder AD severity compared to the patients included in our study. Only two studies investigated the relationship between peripheral 24S-OHC and severity of cognitive impairment. Those studies reported lower 24S-OHC levels in patients with moderate-to-severe $\mathrm{AD}$ (mean: $20.05 \mathrm{ng} / \mathrm{mL}$ ) versus mild AD (mean: $23.8 \mathrm{ng} / \mathrm{mL}$ ) [76], and in patients with $\mathrm{AD}$ (mean: $47.5 \mathrm{ng} / \mathrm{mL}$ ) versus mild cognitive impairment $(51 \mathrm{ng} / \mathrm{mL})$ or subjective cognitive impairment (mean: $58.4 \mathrm{ng} / \mathrm{mL}$ ) [77]. Though the mean $24 \mathrm{~S}-\mathrm{OHC}$ level of patients in our study (mean: $14.7 \mathrm{ng} / \mathrm{mL}$ ) was lower than that of Papassotiropoulos et al. [76] and Solomon et al. [77], our study included patients of much greater AD severity, further supporting a decrease in $24 \mathrm{~S}-\mathrm{OHC}$ levels in the advanced stages of AD.

Interestingly, the association found between 24SOHC and CMAI IPA scores on the cross-sectional and longitudinal analyses differed from findings with the CMAI total score. This suggests that the IPA criteria may reflect a more biological definition of agitation than what is reflected by the CMAI total score. Specifically, the absence of verbal non-aggressive symptoms (e.g., complaining and negativism) from the CMAI IPA score suggests that those symptoms may not be linked to these underlying neurobiologic changes. Consistent with the IPA definition, this may suggest that those symptoms may be more strongly linked to external factors that can be treated with 
nonpharmacological interventions [78]. Few studies have investigated differences in the neurobiology and efficacy of pharmacological interventions based on agitation subtype [79]. However, given the relatively recent publication of the IPA criteria, it is anticipated that future studies will investigate subtypes of agitation further, which may strengthen the evidence regarding the neurobiology of agitation, and the differential efficacy of interventions based on type of agitation.

The investigation of biomarkers has been identified as an important area of research by the FDA-NIH Biomarker Work Group (FDA-NIH-BWG), who has defined a number of terms relevant to study endpoints and biomarkers through the Biomarkers, EndpointS, and other Tools (BEST) resource [80]. With respect to this trial, we were able to investigate the diagnostic, prognostic, predictive, and monitoring capacity of $24 \mathrm{~S}-\mathrm{OHC}$ by collecting $24 \mathrm{~S}-\mathrm{OHC}$ and measurements of agitation at the start and end of each phase. Specifically, our cross-sectional analysis at baseline allowed us to investigate $24 \mathrm{~S}-\mathrm{OHC}$ as a diagnostic marker; a marker that can be used to confirm the presence or severity of a symptom. By investigating the association between baseline 24S-OHC and changes in agitation severity, we were able to investigate the predictive and prognostic capacity of $24 \mathrm{~S}-\mathrm{OHC}$ in the nabilone and placebo phases, respectively. Finally, by investigating whether changes in $24 \mathrm{~S}-\mathrm{OHC}$ were associated with changes in agitation severity, we were able to investigate the monitoring capacity of 24S$\mathrm{OHC}$, providing insight on the biological relationship between 24S-OHC and agitation. In a comprehensive systematic review, our group highlighted the importance of conducting longitudinal studies to investigate the predictive/prognostic and monitoring capacity of biomarkers of agitation as most studies to date have only investigated the diagnostic nature of biomarkers in cross-sectional studies [75]. This study is one of few studies to contribute evidence regarding the neurobiology of agitation on a longitudinal level.

Future studies investigating the relationship between $24 \mathrm{~S}-\mathrm{OHC}$ and agitation and response to nabilone are needed to allow researchers to work towards validating and qualifying this biomarker. In order to validate $24 \mathrm{~S}-\mathrm{OHC}$ for agitation and response, researchers would need to confirm its sensitivity and specificity. This includes incorporating comprehensive analytical assessment methods such as $2 \times 2$ contingency tables to identify the proportion of false negatives/positives for predicting clinical outcomes with or without drug treatment. Once this marker has been sufficiently validated, investigators may consider submitting this marker for qualification through FDA's Biomarker Qualification Program [80].

\section{Limitations}

Our sample size of 38 limited our ability to investigate the effects of multiple covariates. However, this was a preliminary investigation that has provided the insight necessary to rationalize the need for future studies investigating the relationship between brain cholesterol metabolism and agitation in patients with AD. This study included only patients with moderate-to-severe $\mathrm{AD}$ and clinically significant agitation. Therefore, our cross-sectional findings do not provide insight into the diagnostic capacity of 24SOHC to detect agitation, but rather provide support for $24 \mathrm{~S}-\mathrm{OHC}$ as a marker of agitation severity in patients with $\mathrm{AD}$. Another potential limitation is that the association between $24 \mathrm{~S}-\mathrm{OHC}$ and agitation may actually be due to increasing AD severity. However, there was no significant association between 24S$\mathrm{OHC}$ and sMMSE scores at baseline. Since agitation increases in prevalence and severity with $\mathrm{AD}$ progression [81], it is possible that our findings are due to a combination of agitation and increasing severity of cognitive impairment.

We did not select participants based on degree of brain atrophy, or AD-specific markers such as amyloid-beta plaque or tau burden. Though these measurements would provide a more accurate diagnosis of $\mathrm{AD}$, the collection of these measurements would not be feasible in our elderly and frail patient population as they would not be able to tolerate neuroimaging or lumbar punctures for CSF measurements.

This study focused on $24 \mathrm{~S}-\mathrm{OHC}$ and did not measure other cholesterol metabolites such as 27hydroxycholesterol (27-OHC). As $24 \mathrm{~S}-\mathrm{OHC}$ is brain-derived, and $27-\mathrm{OHC}$ is predominantly peripherally derived, 24S-OHC may better reflect brain cholesterol metabolism. Nevertheless, 27-OHC can cross the blood-brain barrier, which may allow it to impact brain cholesterol homeostasis, membrane fluidity and ECS signaling [21]. However, as 27-OHC levels in the brain are about 10-fold less than that of 24S-OHC [21, 82], 27-OHC may not have as large of an impact on brain cholesterol homeostasis as 24-OHC. This study did not collect peripheral cholesterols levels, which have been used in previous studies 
to infer central processes [83-85]. Unlike 24S-OHC, peripheral cholesterol is more likely to be influenced by diet, physical activity, and medications, all of which may be impacted in aging and $\mathrm{AD}$ [86]. Additionally, the blood-brain barrier prevents the transport of cholesterol from the periphery to the brain, and vice versa [87]. Consequently, caution should be used when inferring that peripheral cholesterol levels reflect cholesterol levels in the brain which in turn are associated with other central processes. Cholesterol precursors such as lanosterol, desmosterol, and lathosterol which are both centrally and peripherally located may be of interest when investigating cholesterol metabolism as changes to their levels may reflect altered de novo synthesis, a process known to occur in patients with $\mathrm{AD}[88,89]$. Although $24 \mathrm{~S}-\mathrm{OHC}$ is the only brain cholesterol metabolite that can be measured in the periphery, an advantage of investigating cholesterol, precursors of cholesterol and other nonbrain derived cholesterol metabolites would include analysis using ratios (e.g., 24S-OHC:cholesterol). This would provide insight regarding whether only brain cholesterol metabolism, or its combination with peripheral cholesterol metabolism are associated with the presence and/or severity of agitation.

\section{Conclusions}

Our findings suggest that serum 24S-OHC may be a marker of agitation severity in patients with moderate to severe $\mathrm{AD}$. Though baseline and change in 24S-OHC did not predict response to nabilone, they were both associated with changes in agitation in the placebo phase, supporting a biological association between brain cholesterol metabolism and agitation severity in AD. Preclinical studies with CB compounds are needed to confirm whether $\mathrm{CB}$ have the ability modulate CYP46A1 expression and activity through a reduction of neuroinflammation and oxidative stress. Future studies should consider the inclusion of other biomarkers such as markers of AD pathology and other cholesterol metabolites to elucidate whether other biological processes are involved in the association between $24 \mathrm{~S}-\mathrm{OHC}$ and agitation severity. Finally, as this was a preliminary study on the association between 24S-OHC and agitation in patients with $\mathrm{AD}$, future studies with larger sample sizes and which investigate the cross-sectional and longitudinal relationships between 24S-OHC and agitation are needed to confirm our findings and validate the use of $24 \mathrm{~S}-\mathrm{OHC}$ as a diagnostic, predictive, and monitoring marker of agitation severity in $\mathrm{AD}$.

\section{ACKNOWLEDGMENTS}

This study was jointly funded by the Alzheimer Society of Canada and the Alzheimer's Drug Discovery Foundation, and the Canadian Consortium on Neurodegeneration in Aging.

Authors' disclosures available online (https:// www.j-alz.com/manuscript-disclosures/19-0202r1).

\section{REFERENCES}

[1] Zahodne LB, Ornstein K, Cosentino S, Devanand DP, Stern Y (2015) Longitudinal relationships between Alzheimer disease progression and psychosis, depressed mood, and agitation/aggression. Am J Geriatr Psychiatry 23, 130-140.

[2] Herrmann N, Gauthier S (2008) Diagnosis and treatment of dementia: 6. Management of severe Alzheimer disease. CMAJ 179, 1279-1287.

[3] Lyketsos CG, Lopez O, Jones B, Fitzpatrick AL, Breitner J, DeKosky S (2002) Prevalence of neuropsychiatric symptoms in dementia and mild cognitive impairment: Results from the Cardiovascular Health Study. JAMA 288, 14751483 .

[4] McKeith I, Cummings J (2005) Behavioural changes and psychological symptoms in dementia disorders. Lancet Neurol 4, 735-742.

[5] Margallo-Lana M, Swann A, O'Brien J, Fairbairn A, Reichelt K, Potkins D, Mynt P, Ballard C (2001) Prevalence and pharmacological management of behavioural and psychological symptoms amongst dementia sufferers living in care environments. Int J Geriatr Psychiatry 16, 39-44.

[6] Pitkala KH, Laurila JV, Strandberg TE, Tilvis RS (2004) Behavioral symptoms and the administration of psychotropic drugs to aged patients with dementia in nursing homes and in acute geriatric wards. Int Psychogeriatr 16, 61-74.

[7] Zuidema SU, de Jonghe JF, Verhey FR, Koopmans RT (2007) Agitation in Dutch institutionalized patients with dementia: Factor analysis of the Dutch version of the Cohen-Mansfield Agitation Inventory. Dement Geriatr Cogn Disord 23, 35-41.

[8] Shin IS, Carter M, Masterman D, Fairbanks L, Cummings JL (2005) Neuropsychiatric symptoms and quality of life in Alzheimer disease. Am J Geriatr Psychiatry 13, 469-474.

[9] Miller EA, Schneider LS, Rosenheck RA (2011) Predictors of nursing home admission among Alzheimer's disease patients with psychosis and/or agitation. Int Psychogeriatr 23, 44-53.

[10] Mohamed S, Rosenheck R, Lyketsos CG, Schneider LS (2010) Caregiver burden in Alzheimer disease: Crosssectional and longitudinal patient correlates. Am J Geriatr Psychiatry 18, 917-927.

[11] Tschanz JT, Norton MC, Zandi PP, Lyketsos CG (2013) The Cache County Study on Memory in Aging: Factors affecting risk of Alzheimer's disease and its progression after onset. Int Rev Psychiatry 25, 673-685.

[12] Schneider LS, Dagerman K, Insel PS (2006) Efficacy and adverse effects of atypical antipsychotics for dementia: Meta-analysis of randomized, placebo-controlled trials. Am J Geriatr Psychiatry 14, 191-210.

[13] Ballard C, Lana MM, Theodoulou M, Douglas S, McShane R, Jacoby R, Kossakowski K, Yu LM, Juszczak E, Investigators DA (2008) A randomised, blinded, placebo-controlled 
trial in dementia patients continuing or stopping neuroleptics (the DART-AD trial). PLoS Med 5, e76.

[14] Schneider LS, Dagerman KS, Insel P (2005) Risk of death with atypical antipsychotic drug treatment for dementia: Meta-analysis of randomized placebo-controlled trials. JAMA 294, 1934-1943.

[15] Pappolla MA, Smith MA, Bryant-Thomas T, Bazan N, Petanceska S, Perry G, Thal LJ, Sano M, Refolo LM (2002) Cholesterol, oxidative stress, and Alzheimer's disease: Expanding the horizons of pathogenesis. Free Radic Biol Med 33, 173-181.

[16] Gamba P, Testa G, Gargiulo S, Staurenghi E, Poli G, Leonarduzzi G (2015) Oxidized cholesterol as the driving force behind the development of Alzheimer's disease. Front Aging Neurosci 7, 119.

[17] Vance JE (2012) Dysregulation of cholesterol balance in the brain: Contribution to neurodegenerative diseases. Dis Model Mech 5, 746-755.

[18] Lutjohann D, Papassotiropoulos A, Bjorkhem I, Locatelli S, Bagli M, Oehring RD, Schlegel U, Jessen F, Rao ML, von Bergmann K, Heun R (2000) Plasma 24S-hydroxycholesterol (cerebrosterol) is increased in Alzheimer and vascular demented patients. J Lipid Res 41, 195-198.

[19] Lutjohann D, von Bergmann K (2003) 24S-hydroxycholesterol: A marker of brain cholesterol metabolism. Pharmacopsychiatry 36(Suppl 2), S102-S106.

[20] Hughes TM, Kuller LH, Lopez OL, Becker JT, Evans RW, Sutton-Tyrrell K, Rosano C (2012) Markers of cholesterol metabolism in the brain show stronger associations with cerebrovascular disease than Alzheimer's disease. J Alzheimers Dis 30, 53-61.

[21] Hughes TM, Rosano C, Evans RW, Kuller LH (2013) Brain cholesterol metabolism, oxysterols, and dementia. J Alzheimers Dis 33, 891-911.

[22] Testa G, Staurenghi E, Zerbinati C, Gargiulo S, Iuliano L, Giaccone G, Fanto F, Poli G, Leonarduzzi G, Gamba P (2016) Changes in brain oxysterols at different stages of Alzheimer's disease: Their involvement in neuroinflammation. Redox Biol 10, 24-33.

[23] Bielska AA, Schlesinger P, Covey DF, Ory DS (2012) Oxysterols as non-genomic regulators of cholesterol homeostasis. Trends Endocrinol Metab 23, 99-106.

[24] Uriguen L, Perez-Rial S, Ledent C, Palomo T, Manzanares J (2004) Impaired action of anxiolytic drugs in mice deficient in cannabinoid CB1 receptors. Neuropharmacology 46, 966-973.

[25] Steiner MA, Wanisch K, Monory K, Marsicano G, Borroni E, Bachli H, Holsboer F, Lutz B, Wotjak CT (2008) Impaired cannabinoid receptor type 1 signaling interferes with stresscoping behavior in mice. Pharmacogenomics $J$ 8, 196-208.

[26] Bari M, Paradisi A, Pasquariello N, Maccarrone M (2005) Cholesterol-dependent modulation of type 1 cannabinoid receptors in nerve cells. J Neurosci Res 81, 275-283.

[27] Dietschy JM, Turley SD (2001) Cholesterol metabolism in the brain. Curr Opin Lipidol 12, 105-112.

[28] Bari M, Battista N, Fezza F, Finazzi-Agro A, Maccarrone M (2005) Lipid rafts control signaling of type-1 cannabinoid receptors in neuronal cells. Implications for anandamideinduced apoptosis. J Biol Chem 280, 12212-12220.

[29] Passmore MJ (2008) The cannabinoid receptor agonist nabilone for the treatment of dementia-related agitation. Int J Geriatr Psychiatry 23, 116-117.

[30] Herrmann N, Ruthirakuhan M, Gallagher D, Verhoeff NPLG, Kiss A, Black SE, Lanctôt KL (2019) Randomized placebo controlled trial of nabilone for agitation in Alzheimer's disease. Am J Geriatr Psychiatry. doi: 10.1016/j.jagp.2019.05.002

[31] Hampson AJ, Grimaldi M, Axelrod J, Wink D (1998) Cannabidiol and (-)Delta9-tetrahydrocannabinol are neuroprotective antioxidants. Proc Natl Acad Sci U S A 95, 8268-8273.

[32] Nagarkatti P, Pandey R, Rieder SA, Hegde VL, Nagarkatti M (2009) Cannabinoids as novel anti-inflammatory drugs. Future Med Chem 1, 1333-1349.

[33] Cohen-Mansfield J (1989) Agitation in the elderly. Adv Psychosom Med 19, 101-113.

[34] Sidhu R, Jiang H, Farhat NY, Carrillo-Carrasco N, Woolery M, Ottinger E, Porter FD, Schaffer JE, Ory DS, Jiang X (2015) A validated LC-MS/MS assay for quantification of 24(S)-hydroxycholesterol in plasma and cerebrospinal fluid. J Lipid Res 56, 1222-1233.

[35] Cummings J, Mintzer J, Brodaty H, Sano M, Banerjee S, Devanand DP, Gauthier S, Howard R, Lanctot K, Lyketsos CG, Peskind E, Porsteinsson AP, Reich E, Sampaio C, Steffens D, Wortmann M, Zhong K, International Psychogeriatric Association (2015) Agitation in cognitive disorders: International Psychogeriatric Association provisional consensus clinical and research definition. Int Psychogeriatr 27, 7-17.

[36] Jones KT, Zhen J, Reith ME (2012) Importance of cholesterol in dopamine transporter function. J Neurochem $\mathbf{1 2 3}$, 700-715.

[37] Meljon A, Wang Y, Griffiths WJ (2014) Oxysterols in the brain of the cholesterol 24-hydroxylase knockout mouse. Biochem Biophys Res Commun 446, 768-774.

[38] Rantham Prabhakara JP, Feist G, Thomasson S, Thompson A, Schommer E, Ghribi O (2008) Differential effects of 24hydroxycholesterol and 27-hydroxycholesterol on tyrosine hydroxylase and alpha-synuclein in human neuroblastoma SH-SY5Y cells. J Neurochem 107, 1722-1729.

[39] Cantarelli Mda G, Tramontina AC, Leite MC, Goncalves CA (2014) Potential neurochemical links between cholesterol and suicidal behavior. Psychiatry Res 220, 745-751.

[40] Paul SM, Doherty JJ, Robichaud AJ, Belfort GM, Chow BY, Hammond RS, Crawford DC, Linsenbardt AJ, Shu HJ, Izumi Y, Mennerick SJ, Zorumski CF (2013) The major brain cholesterol metabolite 24(S)-hydroxycholesterol is a potent allosteric modulator of N-methyl-D-aspartate receptors. J Neurosci 33, 17290-17300.

[41] Itoh M, Meguro K, Fujiwara T, Hatazawa J, Iwata R, Ishiwata K, Takahashi T, Ido T, Sasaki H (1994) Assessment of dopamine metabolism in brain of patients with dementia by means of $18 \mathrm{~F}$-fluorodopa and PET. Ann Nucl Med $\mathbf{8}$, 245-251.

[42] Reeves S, Brown R, Howard R, Grasby P (2009) Increased striatal dopamine (D2/D3) receptor availability and delusions in Alzheimer disease. Neurology 72, 528-534.

[43] Blin J, Baron JC, Dubois B, Crouzel C, Fiorelli M, AttarLevy D, Pillon B, Fournier D, Vidailhet M, Agid Y (1993) Loss of brain 5-HT2 receptors in Alzheimer's disease. In vivo assessment with positron emission tomography and [18F]setoperone. Brain 116(Pt 3), 497-510.

[44] Meltzer CC, Smith G, DeKosky ST, Pollock BG, Mathis CA, Moore RY, Kupfer DJ, Reynolds CF 3rd (1998) Serotonin in aging, late-life depression, and Alzheimer's disease: The emerging role of functional imaging. Neuropsychopharmacology 18, 407-430.

[45] Bai X, Edden RA, Gao F, Wang G, Wu L, Zhao B, Wang M, Chan Q, Chen W, Barker PB (2015) Decreased gamma-aminobutyric acid levels in the parietal region of 
patients with Alzheimer's disease. J Magn Reson Imaging 41, 1326-1331.

[46] Lanctot KL, Herrmann N, van Reekum R, Eryavec G, Naranjo CA (2002) Gender, aggression and serotonergic function are associated with response to sertraline for behavioral disturbances in Alzheimer's disease. Int J Geriatr Psychiatry 17, 531-541.

[47] Herrmann N, Rothenburg LS, Black SE, Ryan M, Liu BA, Busto UE, Lanctot KL (2008) Methylphenidate for the treatment of apathy in Alzheimer disease: Prediction of response using dextroamphetamine challenge. J Clin Psychopharmacol 28, 296-301.

[48] Herrmann N, Lanctot KL, Khan LR (2004) The role of norepinephrine in the behavioral and psychological symptoms of dementia. J Neuropsychiatry Clin Neurosci 16, 261-276.

[49] Lanctot KL, Herrmann N, Rothenburg L, Eryavec G (2007) Behavioral correlates of GABAergic disruption in Alzheimer's disease. Int Psychogeriatr 19, 151-158.

[50] Cheer JF, Wassum KM, Heien ML, Phillips PE, Wightman RM (2004) Cannabinoids enhance subsecond dopamine release in the nucleus accumbens of awake rats. J Neurosci 24, 4393-4400.

[51] Pistis M, Perra S, Pillolla G, Melis M, Muntoni AL, Gessa GL (2004) Adolescent exposure to cannabinoids induces long-lasting changes in the response to drugs of abuse of rat midbrain dopamine neurons. Biol Psychiatry 56, 86-94.

[52] Kirilly E, Hunyady L, Bagdy G (2013) Opposing local effects of endocannabinoids on the activity of noradrenergic neurons and release of noradrenaline: Relevance for their role in depression and in the actions of $\mathrm{CB}(1)$ receptor antagonists. J Neural Transm (Vienna) 120, 177-186.

[53] Haj-Dahmane S, Shen RY (2011) Modulation of the serotonin system by endocannabinoid signaling. $\mathrm{Neu}$ ropharmacology 61, 414-420.

[54] Best AR, Regehr WG (2008) Serotonin evokes endocannabinoid release and retrogradely suppresses excitatory synapses. J Neurosci 28, 6508-6515.

[55] Sigel E, Baur R, Racz I, Marazzi J, Smart TG, Zimmer A, Gertsch J (2011) The major central endocannabinoid directly acts at GABA(A) receptors. Proc Natl Acad Sci U S A 108, 18150-18155.

[56] Spivak CE, Lupica CR, Oz M (2007) The endocannabinoid anandamide inhibits the function of alpha4beta2 nicotinic acetylcholine receptors. Mol Pharmacol 72, 1024-1032.

[57] Kolsch H, Heun R, Kerksiek A, Bergmann KV, Maier W, Lutjohann D (2004) Altered levels of plasma 24S- and 27hydroxycholesterol in demented patients. Neurosci Lett $\mathbf{3 6 8}$, 303-308

[58] Ohyama Y, Meaney S, Heverin M, Ekstrom L, Brafman A, Shafir M, Andersson U, Olin M, Eggertsen G, Diczfalusy U, Feinstein E, Bjorkhem I (2006) Studies on the transcriptional regulation of cholesterol 24-hydroxylase (CYP46A1): Marked insensitivity toward different regulatory axes. J Biol Chem 281, 3810-3820.

[59] Testa G, Gamba P, Badilli U, Gargiulo S, Maina M, Guina T, Calfapietra S, Biasi F, Cavalli R, Poli G, Leonarduzzi G (2014) Loading into nanoparticles improves quercetin's efficacy in preventing neuroinflammation induced by oxysterols. PLoS One 9, e96795.

[60] Joffre C, Leclere L, Buteau B, Martine L, Cabaret S, Malvitte L, Acar N, Lizard G, Bron A, Creuzot-Garcher C, Bretillon L (2007) Oxysterols induced inflammation and oxidation in primary porcine retinal pigment epithelial cells. Curr Eye Res 32, 271-280.
[61] Lemaire-Ewing S, Prunet C, Montange T, Vejux A, Berthier A, Bessede G, Corcos L, Gambert P, Neel D, Lizard G (2005) Comparison of the cytotoxic, pro-oxidant and proinflammatory characteristics of different oxysterols. Cell Biol Toxicol 21, 97-114.

[62] Wolff V, Schlagowski AI, Rouyer O, Charles AL, Singh F, Auger C, Schini-Kerth V, Marescaux C, Raul JS, Zoll J, Geny B (2015) Tetrahydrocannabinol induces brain mitochondrial respiratory chain dysfunction and increases oxidative stress: A potential mechanism involved in cannabis-related stroke. Biomed Res Int 2015, 323706.

[63] Gao Y, Zhuang Z, Gao S, Li X, Zhang Z, Ye Z, Li L, Tang C, Zhou M, Han X, Li J (2017) Tetrahydrocurcumin reduces oxidative stress-induced apoptosis via the mitochondrial apoptotic pathway by modulating autophagy in rats after traumatic brain injury. Am J Transl Res 9, 887-899.

[64] Puffenbarger RA, Boothe AC, Cabral GA (2000) Cannabinoids inhibit LPS-inducible cytokine mRNA expression in rat microglial cells. Glia 29, 58-69.

[65] Kozela E, Juknat A, Kaushansky N, Rimmerman N, Ben-Nun A, Vogel Z (2013) Cannabinoids decrease the th17 inflammatory autoimmune phenotype. JNeuroimmune Pharmacol 8, 1265-1276.

[66] Arlt S, Brassen S, Jahn H, Wilke F, Eichenlaub M, Apostolova I, Wenzel F, Thiele F, Young S, Buchert R (2009) Association between FDG uptake, CSF biomarkers and cognitive performance in patients with probable Alzheimer's disease. Eur J Nucl Med Mol Imaging 36, 1090-1100.

[67] Mosconi L, Tsui WH, Herholz K, Pupi A, Drzezga A, Lucignani G, Reiman EM, Holthoff V, Kalbe E, Sorbi S, Diehl-Schmid J, Perneczky R, Clerici F, Caselli R, Beuthien-Baumann B, Kurz A, Minoshima S, de Leon MJ (2008) Multicenter standardized 18F-FDG PET diagnosis of mild cognitive impairment, Alzheimer's disease, and other dementias. J Nucl Med 49, 390-398.

[68] Landau SM, Harvey D, Madison CM, Koeppe RA, Reiman EM, Foster NL, Weiner MW, Jagust WJ, Alzheimer's Disease Neuroimaging Initiative (2011) Associations between cognitive, functional, and FDG-PET measures of decline in AD and MCI. Neurobiol Aging 32, 1207-1218.

[69] $\mathrm{Ng} \mathrm{KP}$, Pascoal TA, Mathotaarachchi S, Chung CO, Benedet AL, Shin M, Kang MS, Li X, Ba M, Kandiah N, Rosa-Neto P, Gauthier S, Alzheimer's Disease Neuroimaging Initiative (2017) Neuropsychiatric symptoms predict hypometabolism in preclinical Alzheimer disease. Neurology 88, 1814-1821.

[70] Sultzer DL, Mahler ME, Mandelkern MA, Cummings JL, Van Gorp WG, Hinkin CH, Berisford MA (1995) The relationship between psychiatric symptoms and regional cortical metabolism in Alzheimer's disease. J Neuropsychiatry Clin Neurosci 7, 476-484.

[71] Weissberger GH, Melrose RJ, Narvaez TA, Harwood D, Mandelkern MA, Sultzer DL (2017) (18)F-fluorodeoxyglucose positron emission tomography cortical metabolic activity associated with distinct agitation behaviors in Alzheimer disease. Am J Geriatr Psychiatry 25, 569-579.

[72] Reiman EM, Chen K, Caselli RJ, Alexander GE, Bandy D, Adamson JL, Lee W, Cannon A, Stephan EA, Stephan DA, Papassotiropoulos A (2008) Cholesterol-related genetic risk scores are associated with hypometabolism in Alzheimer'saffected brain regions. Neuroimage 40, 1214-1221.

[73] Xiong H, Callaghan D, Jones A, Walker DG, Lue LF, Beach TG, Sue LI, Woulfe J, Xu H, Stanimirovic DB, Zhang W (2008) Cholesterol retention in Alzheimer's brain is 
responsible for high beta- and gamma-secretase activities and Abeta production. Neurobiol Dis 29, 422-437.

[74] Li Y (2010) Effect of cholesterol in CSF on tau phosphorylation. Alzheimers Dement 6, S276.

[75] Ruthirakuhan M, Lanctot KL, Di Scipio M, Ahmed M, Herrmann N (2018) Biomarkers of agitation and aggression in Alzheimer's disease: A systematic review. Alzheimers Dement 14, 1344-1376.

[76] Papassotiropoulos A, Lutjohann D, Bagli M, Locatelli S, Jessen F, Rao ML, Maier W, Bjorkhem I, von Bergmann K, Heun R (2000) Plasma 24S-hydroxycholesterol: A peripheral indicator of neuronal degeneration and potential state marker for Alzheimer's disease. Neuroreport 11, 19591962.

[77] Solomon A, Leoni V, Kivipelto M, Besga A, Oksengard AR, Julin P, Svensson L, Wahlund LO, Andreasen N, Winblad B, Soininen H, Bjorkhem I (2009) Plasma levels of 24S-hydroxycholesterol reflect brain volumes in patients without objective cognitive impairment but not in those with Alzheimer's disease. Neurosci Lett 462, 89-93.

[78] Cohen-Mansfield J (2001) Nonpharmacologic interventions for inappropriate behaviors in dementia: A review, summary, and critique. Am J Geriatr Psychiatry 9, 361-381.

[79] Husebo BS, Ballard C, Cohen-Mansfield J, Seifert R, Aarsland D (2014) The response of agitated behavior to pain management in persons with dementia. Am J Geriatr Psychiatry 22, 708-717.

[80] BEST (Biomarkers, EndpointS, and other Tools) Resource, FDA-NIH Biomarker Working Group, https://www.ncbi. nlm.nih.gov/pubmed/27010052,

[81] Steinberg M, Shao H, Zandi P, Lyketsos CG, Welsh-Bohmer KA, Norton MC, Breitner JC, Steffens DC, Tschanz JT, Cache County Investigators (2008) Point and 5-year period prevalence of neuropsychiatric symptoms in dementia: The Cache County Study. Int J Geriatr Psychiatry 23, 170-177.
[82] Umetani M, Shaul PW (2011) 27-Hydroxycholesterol: The first identified endogenous SERM. Trends Endocrinol Metab 22, 130-135.

[83] Vilibic M, Jukic V, Pandzic-Sakoman M, Bilic P, Milosevic M (2014) Association between total serum cholesterol and depression, aggression, and suicidal ideations in war veterans with posttraumatic stress disorder: A cross-sectional study. Croat Med J 55, 520-529.

[84] Elias PK, Elias MF, D'Agostino RB, Sullivan LM, Wolf PA (2005) Serum cholesterol and cognitive performance in the Framingham Heart Study. Psychosom Med 67, 24-30.

[85] Chen H, Du Y, Liu S, Ge B, Ji Y, Huang G (2019) Association between serum cholesterol levels and Alzheimer's disease in China: A case-control study. Int J Food Sci Nutr 70, 405-411.

[86] Cox RA, Garcia-Palmieri MR (1990) Cholesterol, triglycerides, and associated lipoproteins. In Clinical Methods: The History, Physical, and Laboratory Examinations, Walker HK, Hall WD, Hurst JW, eds., Boston.

[87] Bjorkhem I (2006) Crossing the barrier: Oxysterols as cholesterol transporters and metabolic modulators in the brain. J Intern Med 260, 493-508.

[88] Zhang J, Liu Q (2015) Cholesterol metabolism and homeostasis in the brain. Protein Cell 6, 254-264.

[89] Kolsch H, Heun R, Jessen F, Popp J, Hentschel F, Maier W, Lutjohann D (2010) Alterations of cholesterol precursor levels in Alzheimer's disease. Biochim Biophys Acta 1801, 945-950. 